\title{
THE CHEMICAL EQUILIBRIA RELATING THE ISOTOPIC HYOAOGENS AT LOW TEMPERATURES
}

J. W. Pyper and P. C. Souers

Decouber 1, 1976

\section{MSTER}

Prepared for U.S. Energy Research $:$ Development

Administration under contract No. W-7405-Eng-48

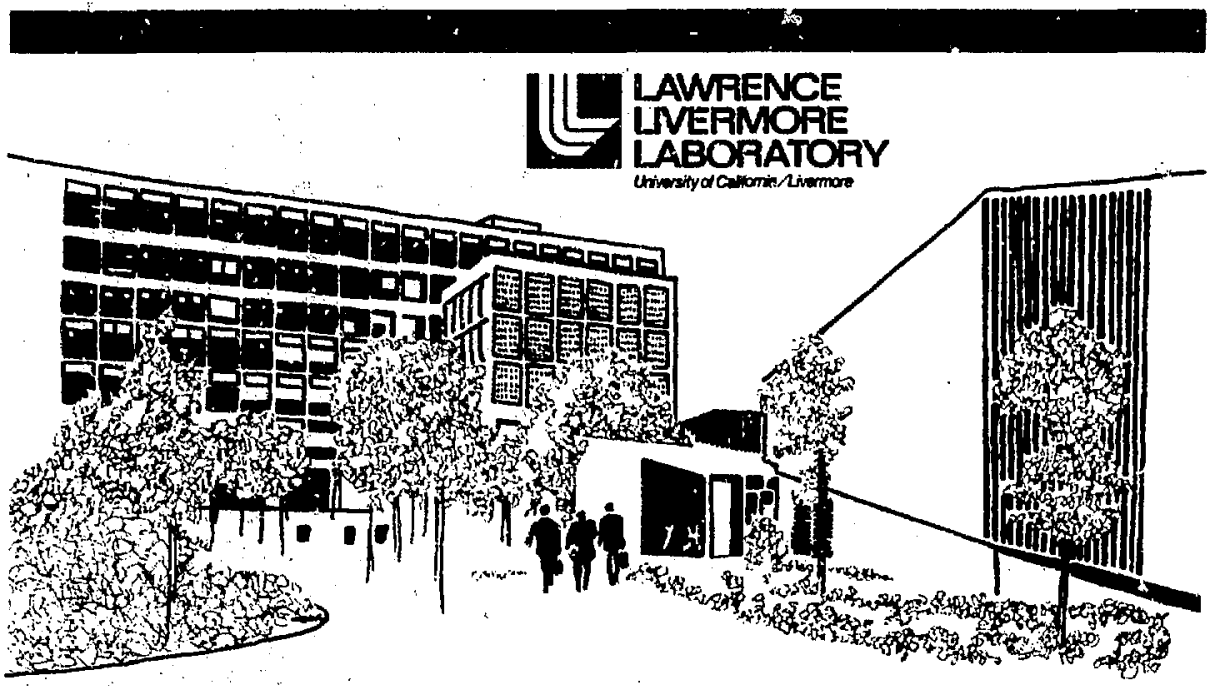




\section{NOTCE}

Thi mport vas pripared a in sccount of work aponod by the Untred Sut en Goverament. Neither the

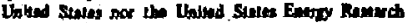
a Derropment Administration, nor any of thelr imployme, nox any of their contractors, wheontractors, or thetr employwes mates any warrenty, expres or inpilod, of exume any lopl libillty oe repondblity

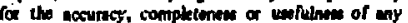
informetion, apperatut, product of proces dickind, of inprecents the lis une would not infiling privately owned rishts.

\section{NOTICE}

Refirence to 1 compeny or product nume does not imply spproml or recommendution of the product by the Untwerdty of Cellyornis or the US. Eserpy Rewarch 1. Derwopanent Adminidtation to the exclusion of olhen thet may be wituble.

Priated in the United States of Amerlea Avaikble from

Nationd Technlal Information Service

U.S. Depurtment of Commerce

S285 Porl Royal Roud

Springfield, VA 22161

Ptice: Printed Copy 5 ; Microliche $\mathbf{3 3 . 0 0}$

\begin{tabular}{|c|c|c|c|}
\hline Pus Ruse & Drimitic & Roseres & $\begin{array}{c}\text { Domestic } \\
\text { Priton }\end{array}$ \\
\hline $\begin{array}{l}001-025 \\
026-050 \\
051-075\end{array}$ & $\begin{array}{r}53.50 \\
4.00 \\
4.50\end{array}$ & $\begin{array}{l}326-350 \\
351-375 \\
376-400\end{array}$ & $\begin{array}{l}10.00 \\
1050 \\
10.75\end{array}$ \\
\hline $076-100$ & 5.00 & $401-425$ & 11.00 \\
\hline $10 \mathrm{t}-125$ & 5.50 & $426-450$ & 11.75 \\
\hline $126-150$ & 6.00 & $451-475$ & 12.00 \\
\hline $15 t-175$ & 6.75 & $476-500$ & 12.50 \\
\hline $176-200$ & 7.50 & SOI-525 & 12.75 \\
\hline $201-225$ & 7.75 & $526-550$ & 13.00 \\
\hline $226-250$ & 8.00 & $551-575$ & 13.50 \\
\hline $251-275$ & 9.00 & $576-600$ & 13.75 \\
\hline $276-300$ & 9.25 & 601-up & 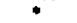 \\
\hline $501-325$ & 9.75 & & \\
\hline
\end{tabular}

Add 2-2.50 for each additional 100 pago increment from 601 to 1,000 para;

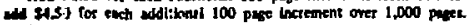




\section{년 \\ LAWFENCE LNEFMORE LAEORATOAY

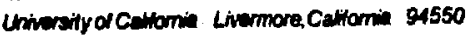

UCRL-52104

\section{THE CHEMICAL EQUILIBRIA RELATING THE ISOTOPIC HYDROGENS AT LOW TEMPERATURES}
J. W. Pyper
P. C. Souers

MS. date: December 1, 1976

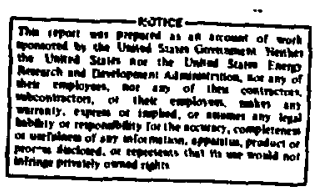




\section{Contents}

Abstract ......................... 1

Introduction ....................... 1

Theory of Isotopic Exchange Reactions ... . . . . . . . . 3

General Bigeleisen-Mayer Theory and Corrections........ . 3

Ortho and Para Forns of the Hydrogen Isotones . . . . . . . . 7

Rotational Corrections to the Equilibrium Constant . . . . . . 8

Qualitative implications of the Theory ............ 9

Survey of the Literature for $\mathrm{K}_{\mathrm{HD}}, \mathrm{K}_{\mathrm{HT}}$, and $\mathrm{K}_{\mathrm{DT}} \ldots \ldots \ldots . \ldots . \ldots 12$

The Equilibrium Constant $\mathrm{K}_{\text {HD }} \ldots \ldots \ldots \ldots$

The Equilibrium Constant $k_{\text {ut }} \ldots \ldots . \ldots 16$

The Equilibrium Constant $k_{\mathrm{jT}} \ldots \ldots \ldots$

Calculation of $K_{H D}, K_{H T}$, and $K_{\mathrm{DT}}$ at Temperatcres Between 4.2 and $50 \mathrm{~K}, \ldots 21$ Conclusions and Proposals for Future lork . . . . . . . . . . . 28 Acknowledgments . . . . . . . . . . . . . . . . 2 29

Appendix A. Sample Calculation of $k_{\mathrm{DT}}$ at $25 \mathrm{~K} \ldots \ldots . \ldots$ Appendix B. Equations Expressing $k_{H D}, k_{H T}$, and $k_{D T}$ as a Function of

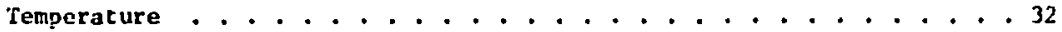

References ........................ 33 


\title{
THE CHEMICAL. EQUILIBRIA RELATING THE ISOTOPIC HYDROGENS AT LOW TEMPERATURES
}

\begin{abstract}
Hydrogen fusion will require a fuel mixturc of ilquefied or frreen $\mathrm{D}_{2}$ and $\mathrm{l}_{2}$. The enmosition of this fucl mixture is described by the equilibrium constant $k_{\text {DT }}$. We discuss in ditall the thecry of lsotopic exchange reactions als it abvlfes to the hydrogen lsotopes. A ilterature survey of the values of $k_{H 11}, k_{H T}$, and $k_{D T}$ found no values of $k_{D T}$. for temperatures below $25 k$ and no values of $K_{l l D}$ and $K_{H T}$ for temperatures below $50 \mathrm{~K}$.

The existing data are criticaliy cvaluaced, and simplefied formulas for the clires equilibriuf constants in the temperature range $50-300 \mathrm{~K}$ are derived from them. rsing harmonic approximation theory with the rotational correction, we bave calculated the vilues of $\mathrm{K}_{H D},{ } \mathrm{HT}_{\mathrm{T}}$, and $\mathrm{K}_{\mathrm{pT}}$ in the temperature range $4.2-50 \mathrm{~K}$. Liv find that $K_{\mathrm{DT}}=2.995 \exp (-10.82 / \mathrm{T})$ in the temperature range 16.7 to $33.3 \mathrm{~K}$ to an at:uraty of $\mathrm{l} \%$. Tables, graphs, and equations of $\mathrm{K}_{\mathrm{HD}}$, $k_{H T}$, and $k_{1 T T}$ are given for the cemperature range 4.2 to $50 \mathrm{~K}$.
\end{abstract}

\section{Introduction}

The recent U.S. energy shortage has stimulated renewed interest in producing power by controlled hydrogen fuslon. This labo.atory and others are pursuing vigorous programs with goals of producing hydrogen fusion through magnetic confinement, electron beams, or laser implosion. All the programs med the fusion fuel that Ignites at the lowest temperature--a mixture of the hydrogen isotopes $D$ and $T$ in the inquid or solid state. The purpose of this report is to collect and evaluate all of the chemical equilibrium data and theory on the isotopic self-exchange reactions of the hydrogen isotopes in all three states of matter: gaseous, liquid, and solid. We also show how simplified theory can be accurately used to predict the values of the equilibrium constants in certain ranges of interest.

Infortunately, we found that, while the equilibrium constants of most interest are those rear the triple points (below $20 \mathrm{~K}$ ) and especially those in the condensed state, almost all of the data available are for the gaseous reactions abcve $50 \mathrm{k}$. We therefore must focus our review on reactions in the gas phase, because of the lack of data on these equilibria in the condensed phases. 
For completeness, we will also survey the data for all the luydrogen isotopes, even though the D-T equilibrium is our main interest.

The isotopic self-exchange reactions of hydrogen are defined in the gas phase as follows:

$$
\begin{aligned}
& \mathrm{H}_{2}(g)+\mathrm{D}_{2}(\mathrm{~g})=2 \mathrm{HD}(\mathrm{g}) ; \\
& \mathrm{H}_{2}(\mathrm{~g})+\mathrm{T}_{2}(\mathrm{~g})=\text { : HT }(\mathrm{g}) ; \\
& \mathrm{D}_{2}(\mathrm{~g})+\mathrm{T}_{2}(\mathrm{~g})=2 \mathrm{DT}(\mathrm{g}) .
\end{aligned}
$$

The equilibrium constants for these reactions are written in the usual way in terms of the measured partial pressures $P_{1}$ of the gaseous spectes 1 :

$$
\begin{aligned}
& \mathrm{K}_{\mathrm{HD}}=\mathrm{P}_{\mathrm{HD}}^{2} / \mathrm{F}_{\mathrm{H}_{2}} \cdot \mathrm{P}_{\mathrm{D}_{2}} ; \\
& \mathrm{K}_{\mathrm{HT}}=\mathrm{P}_{\mathrm{HT}}^{2} / \mathrm{P}_{\mathrm{H}_{2}} \cdot \mathrm{P}_{\mathrm{T}_{2}} ; \\
& \mathrm{K}_{\mathrm{DT}}=\mathrm{P}_{\mathrm{DT}}^{2} / \mathrm{P}_{\mathrm{D}_{2}} \cdot \mathrm{P}_{\mathrm{T}_{2}} .
\end{aligned}
$$

In all cases found in the literature, the partial pressures were determined with a mass spectrometric method.

The equilibrium constants in the liquid and solid phases can be calculated from the gas-phase equilibrium constant, if one knows the vapor pressures of the pure, condensed specles. From Raoult's Law,

$$
\mathrm{P}_{\mathrm{DT}}=\mathrm{N}_{\mathrm{DT}}^{\mathrm{c}} \mathrm{P}_{\mathrm{DT}}^{\mathrm{O}}(\mathrm{c}),
$$

where $\mathrm{N}_{\mathrm{DT}}^{\mathrm{c}}$ signifies the mole fraction of DT in a condensed-phase (11quid, $\ell$, or solid, s) mixture, and $\mathrm{P}_{\mathrm{DT}}^{0}(\mathrm{c})$ represents the vapor pressure of pure DT In the condensed phase. Simllar expressions can be written for the other components. The gas-phase equilibrlum constant can therefore be expressed as

$$
\mathrm{K}_{\mathrm{DT}}(\mathrm{g})=\frac{\mathrm{P}_{\mathrm{DT}}^{2}}{\mathrm{P}_{\mathrm{D}_{2}} \cdot \mathrm{P}_{\mathrm{T}_{2}}}=\left(\frac{\mathrm{N}_{\mathrm{DT}}^{\mathrm{l}^{2}}}{\mathrm{~N}_{\mathrm{D}_{2}}^{\ell} \cdot \mathrm{N}_{\mathrm{T}_{2}}^{\ell}}\right)\left(\frac{\left[\mathrm{P}_{\mathrm{DT}}^{\circ}(\ell)\right]^{2}}{\mathrm{P}_{\mathrm{D}_{2}}^{\mathrm{O}(\ell) \cdot \mathrm{P}_{\mathrm{T}}^{\mathrm{O}}(\ell)}}\right)
$$

when the species in the gas phase are in equilibrium with each other and with the specles in the liquid phase. The liquid-phase equilibrium constant then can be calculated by rearranging Eq. (8):

$$
\mathrm{K}_{\mathrm{DT}}(\ell)=\frac{\mathrm{N}_{\mathrm{DT}}^{\ell^{2}}}{\mathrm{~N}_{\mathrm{D}_{2}}^{\ell} \cdot \mathrm{N}_{\mathrm{T}_{2}}^{\ell}}=K_{\mathrm{DT}}(\mathrm{g})\left(\frac{\mathrm{P}_{\mathrm{D}_{2}(l) \cdot \mathrm{P}_{\mathrm{T}_{2}}^{\mathrm{o}}(\mathrm{l})}}{\left[\mathrm{P}_{\mathrm{DT}}^{\mathrm{o}}(\ell)\right]^{2}}\right) \text {. }
$$


By a similar derivation, we obtain for the case of the gaseous isotopic species in equilibrium with the soldd isotopic species:

$$
\mathrm{K}_{\mathrm{DT}}(s)=\frac{\mathrm{N}_{\mathrm{DT}}^{s^{2}}}{\mathrm{~N}_{\mathrm{D}_{2}}^{s} \cdot \mathrm{N}_{\mathrm{T}}^{\mathrm{s}}}=\mathrm{K}_{\mathrm{DT}}(g)\left(\frac{\mathrm{P}_{2}^{\mathrm{O}}(s) \cdot \mathrm{P}_{\mathrm{T}_{2}}^{\mathrm{o}}{ }^{(s)}}{\left[\mathrm{P}_{\mathrm{DT}}^{\mathrm{o}}(s)\right]^{2}}\right) \text {. }
$$

The relationships would of course be much more complex in the cases where all three phases are in equilibrium with each other. We have not yet derived the necessary equations for these cases. In the above expressions, we have assumed that we are in the low-pressure regime, in which case we can ignore fugacities and activities. At very low temperatures the vapors of the hydrogen Isotopes are quite dense, so fugacities and activities w1ll have to be considered in future experiments.

At most temperatures, the rat lo of the vapor fressures of the pure species ${ }^{l}$ are very close to one. Therefore, $\mathrm{K}_{\mathrm{DT}}(g) \cong \mathrm{K}_{\mathrm{DT}}(\Omega)$ and $\mathrm{K}_{\mathrm{DT}}(\mathrm{g}) \cong \mathrm{K}_{\mathrm{DT}}(s)$ in the appropriate two-phase regions. The same arguments apply to the other systems. This points out the utility of the gas-phase equilibrium constants in estimating the equilibrium constants for the condensed phases. The theory and dat.a developed in the rest of this naper for $\mathrm{k}_{\mathrm{HD}}(\mathrm{g}), \mathrm{K}_{\mathrm{HT}}(\mathrm{g})$, and $\mathrm{K}_{\mathrm{DT}}(\mathrm{g})$ can thus generally be apnlied to equilibria in the condensed phases.

\section{Theory of Isotopic Exchange Reactions}

GENERAL BIGELEISEN-MAYER THEORY AND CORRECTIONS

To calculate the value of an equilibrium constant from theory, we need to know how the molecules are partitioned into the various energy states available to them. If we know this, then we can calculate the equilibrium constant from a simple relationship. The division of molecules in a system into the various energy states is given by the partition function, which is defined as ${ }^{2}$

$$
z=\sum_{j} g_{j} e^{-E_{j} / k T}
$$

where $T$ is the absolute temperature, $k$ is Boltzman's constant, the $\varepsilon_{j}$ 's are the allowed quantum mechanical energy levels for the molecule, and $g_{j}$ is the statistical weight of the $j$ th energy level. The terms $j$ the summation of $z$ indicate how the molecules are partitioned among the various energy levels. 
The equilibrium constant for the hydrogen isotoplc exchange reaction of, for example, Eq. (6) is given by ${ }^{3}$ :

$$
K_{D T}=\frac{\left(\frac{{ }_{D}^{\circ}}{N}\right)^{2}}{\left(\frac{\mathrm{Z}_{\mathrm{D}_{2}}^{\circ}}{\mathrm{N}}\right)\left(\frac{\mathrm{Z}_{\mathrm{T}_{2}}^{\circ}}{\mathrm{N}}\right)} \mathrm{e}^{-\Delta \varepsilon_{0} / k T}
$$

where $z_{1}^{0}$ is the partition function of an 1deal gar 1 in ita standard state, $N$ is Avagadro's number, and $\Delta E_{0}$ is the energy difference hetween comparative chemical stabilities of different chemical systems (someti-es called the zero of energy difference). The N's cancel in Eq. (12), and the exponential term Is equal to one since $\Delta \varepsilon_{0}=0$ for 1sotopic molecules. (According to the Born-Oppenhelmer approximation, ${ }^{1}$ the potential-energy curve for molecule formation is the same for 1sotopic molecules, therefore the zero of energy difference will be zero.)

In addition to the above simplifications, it is convenient to express $K_{D}$ ? in terms of heavy-over-11ght isotopic ratios of $z_{1}$ to take advantage of cancellations that occur. Hence

$$
\mathrm{K}_{\mathrm{DT}}=\left(\frac{\mathrm{Z}_{\mathrm{DT}}^{\mathrm{o}}}{\mathrm{z}_{\mathrm{D}_{2}}^{\mathrm{o}}}\right)\left(\frac{\mathrm{Z}_{\mathrm{T}}^{\mathrm{o}}}{\mathrm{z}_{\mathrm{DT}}^{\mathrm{o}}}\right)^{-1}
$$

Notice that the heavier 1sotope always appears in the numerator nf these ratios.

One of the Implications of the Birn-0ppenheluer approxination ${ }^{1}$ is that one can separate each quantum mechanical energy level into a sum of translational $(t)$, rotational $(r)$, vibrationai $(v)$, and electronic (e) terms. That is

$$
\varepsilon=\varepsilon_{t}+\varepsilon_{r}+\varepsilon_{v}+\varepsilon_{e} \text {. }
$$

It follows that

$$
z=z_{t} z_{r} z_{v} z_{e}
$$

Since for $Z_{t}, Z_{r}$, and $Z_{v}$, the difference between energy levels is often les than kT (the hydrogen 1sotopes at low temperatures are the exception), these 
partition functions can be integrated or sumed ${ }^{4}$ to give the familtar closed-form equations for 1deal gases. Equation (15) therefore becomes

$$
z^{o}(\text { diatomIc molecule })=\left\{\frac{(2 \pi M k T)^{3 / 2} v}{h^{3}}\right\}\left\{\frac{8 \pi^{2} I k T}{\sigma h^{2}}\right\}\left\{\frac{\exp \left(\frac{-h V}{2 k T}\right)}{1-\exp \left(\frac{h V}{k T}\right)}\right\} z_{e^{\prime}}
$$

where

and

$$
\begin{aligned}
& M=\text { the molecular mass; } \\
& \mathbf{b}=\text { plank's constant; } \\
& V=\text { the volume of the gas; } \\
& O=\text { the symmetry number; } \\
& I=\text { the moment of inerita; }
\end{aligned}
$$

$\nu=$ the vibrational frequency.

If we now use this form of the partition function, we can evaluate the ratio in Eq. (13). Taking the rat $10 z_{\mathrm{DT}}^{\circ} / z_{\mathrm{D}_{2}}^{\circ}$ as an example, we obtain

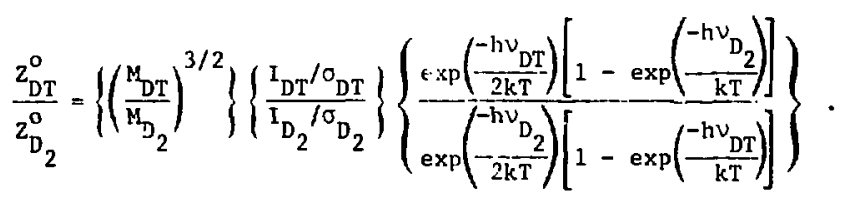

The simplification is obvious: all the factors which are not a function of mass (including $\mathrm{z}_{\mathrm{e}}$ ) cancel. A simpler and more useful ratio can be obtatned if we multiply each side of Eq. (17) by $\left(m_{D} / m_{T}\right)^{3 / 2 n}$ (where $m_{i}$ is the mass of the atom being exchanged and $n$ is the number being exchanged, in this case one) and multiply and divide the right stde by $u_{D_{2}} / u_{D T}$, where $u_{i}=b_{1} / k T$. Equation (17) then becomes

$$
\left(\frac{m_{D}}{m_{T}}\right)^{3 / 2} \frac{z_{D T}^{o}}{z_{D_{2}}^{o}}=\left\{\frac{\sigma_{2}}{\sigma_{D T}}\right\} \frac{{ }_{D T}}{u_{D_{2}}}\left\{\frac{e^{\frac{-u_{D T}}{2}}}{\frac{-u_{D_{2}}}{2}}\right\}\left\{\begin{array}{c}
\frac{\left(1-e^{-u_{2}}\right)}{\left(1-e^{-u_{D T}}\right.} \\
e^{\frac{D^{-}}{2}}
\end{array}\right\},
$$


since

$$
\frac{I_{D T}}{I_{D_{2}}} \cdot\left(\frac{M_{D T}}{M_{2}}\right)^{3 / 2}\left(\frac{m_{D}}{m_{T}}\right)^{3 / 2} \cdot \frac{u_{2}}{u_{D T}}=1
$$

from the Teller-Redlich product rule. ${ }^{5}$ Equatiun (18) Is the BigeleisenMayei ${ }^{6}$ f-function, and is a function only of the symmetry numbers and the vibratlonal trequencles, speciflcally the zero-order or harmonic vibrational frequencles. Since 1947, mist calculat lons of 1sotople equilibrium constants have been made througli this formalism. Equation (19) is val'd for all 1sotopic pairs of molecules except those whose rotations cannot be desiribed by classicil mechanics at the temperature of interest. The rotational energylevel spacings of 1sotopic hydrogen molecules are so much wider than $k T$, even at room temperature, that efther a correction term ${ }^{6}$ must be applied to Eq. (18), or, at low temperatures, the rotational partition function must be evaluated by direct sumation. 7

In the above treatment, a number of approximatioris have been made, ' addition to the Born-oppenheimer approximation. For example, we have treated the rotating molectiles as if they were $r+g i d$ rotors, and the vibrations as if they could be described y simple harmunic motion. We also have assumed that there is no interaction between rotation and vibration. Therefore, if one wants to make a detafled comparisun between theory and experiment, he must be able to calcuiat factors for varlous corrections. The most recent analysis of these corrections has been made by Wolfsberg and his co-workers over the past several years. In Ref. 7, thiy detall the calculat lons of the $G_{0}$ correction, the correction for annarmonic vibration, vibration-rotatio: Interaction, and quantum mechanical rotation. They have also been Invest Igat Ing the possible breakdown of the Born-0ppenheimer approximation. 8

Fortunately, In the special case of lsotoplc self-exchange reactions of hydrogen, the $G_{0}$ correcticn, ${ }^{9}$ the anharmonic vibration correction, ${ }^{9}$ and the correction for the Born-oppenheimer approximation ${ }^{10}$ vanish. The only large correction to the equilibrium constants $F-$ chese reactions is the correction for quantum mechanical rotation, whlch is discussed in a later section. 
ORTHO AND PARA FORMS OF THE HYLROGEN ISOTOPES

This section and the following one detail the necessary correction to $k_{1}$ for quantum mechanical rotation. Neglect of the conslderation of the ortho and para forms of the hyd. gens can lead to incorrect values of the equillbrjum constints, especially at cryogenic temperatures.

At low temperatures, the rotational partition function for the hydrogens annot be expressed in a closed form but must be sumned. The rotational partition function is given by ${ }^{4}$

$$
z_{r}=\sum(2.1+1) \exp \left[-.1(.1+1) \frac{h c B}{k T}\right]
$$

where I is the rotational quantum number, $c$ is the speed of $11 \mathrm{ght}$, and $B_{e}$ is the rutational constant, different for each 1sotope. We define the rotational temperature ${ }_{r}$ as $h c B_{e} / k$, and $f_{i}=\theta_{r} / T$. At a particular remperature, Eq. (20) becomess

$$
z_{r}=\sum(2.1+1) \exp \left[-J(J+1) p_{i}\right]
$$

From quantum mechanics we learn that for homonuclear diatomic molecules, ti: $y$ values in ${ }_{r}$ must be either all odd or all even. 4 If the nuclei are different, there is no restriction on the allowed $J$ valuas. Table 1 gives the definitions of the ortho and para forms ior the homonuclear diatomic hydrogens.

Table 1. Ortho and para hydrogen isotopes.

\begin{tabular}{lcc} 
Molecule & $\begin{array}{c}\text { Even J values allowed } \\
\text { In Eq. (21) }\end{array}$ & $\begin{array}{c}\text { odd J values allowed } \\
\text { in Eq. (21) }\end{array}$ \\
\hline $\mathrm{D}_{2}$ & $\begin{array}{c}\text { Para } \\
\text { Ortho }\end{array}$ & Ortho \\
$\mathrm{T}_{2}$ & Para & Para \\
\hline
\end{tabular}

The even series takes the form:

$$
\left.z_{r} \text { (2ven }\right)=1+5 e^{-\theta_{r} / T}+9 e^{-20 \theta_{r} / T}+\ldots,
$$


and the odd series takes the form:

$$
\mathrm{z}_{\mathrm{r}} \text { (odd) }=3 e^{-26} \mathrm{r} / \mathrm{T}+7 e^{-12 \theta_{\mathrm{r}} / \mathrm{T}}+11 \mathrm{e}^{-30 \theta_{\mathrm{r}} / \mathrm{T}}+\ldots .
$$

The ortho forms in the presence of a conversion catalyst can be converted to the para forms and vice versa. Therefore an equilibrium can be established between the two forms. The calculations in this paper have taken into consideration the various rotational states of the Isotopes and assume an equilibrium mixture of the ortho and para fornls. For equilibrium $D_{2}, z_{r}=2 / 3 z_{r}$ (even) + $1 / 3 \mathrm{Z}_{\mathrm{r}}$ (odd), and for equilibrium $\mathrm{H}_{2}$ alsd $\mathrm{T}_{2}, \mathrm{z}_{\mathbf{r}}=1 / 4 \mathrm{z}_{\mathbf{r}}$ (even) $+3 / 4 \mathrm{Z}_{\mathbf{r}}$ (odd). 11,12

\section{ROTATIONAL CORRECTIONS TO 'IHE EQUIL.TBRIUNI CONSTANT'}

AccordIng to Bigeleisen, ${ }^{11}$ the $\&$ function defined as Eq. (7) In Ref. 6 is equal to:

$$
\mathrm{f}=\frac{\mathrm{Z}_{\mathrm{QM}} / \mathrm{Z}_{\mathrm{QN}}^{\dagger}}{\mathrm{Z}_{\mathrm{C}} / \mathrm{Z}_{\mathrm{C}}^{\prime}}
$$

where QM and $\mathrm{C}$ denote the quantum mechanical and classical partiticn functlons, respectively, and the prime designates the lighter molecule. Breaking the total partition function down into the transiational $(t)$, rotational ( $r$ ), and vibrational (v) parts, we obtain

$$
\mathrm{f}=\frac{z_{Q M}(t) / z_{Q M}^{\prime}(t)}{z_{C}(t) / Z_{C}^{\prime}(t)} \cdot \frac{z_{Q M}(r) / z_{Q M}^{\prime}(r)}{z_{C}(r) / z_{C}^{\prime}(r)} \cdot \frac{z_{Q M}(v) / z_{Q M}^{\prime}(v)}{z_{C}(v) / Z_{C}^{\prime}(v)}
$$

The first ratio (translational) in Eq. (25) is always untty. The third ratio (vibrational) is the usual formulation for $f$ given by Eq. (18). The second ratio (rotational) is unity, except in the case of the hydrogen isotopes, which we study here. Therefore, to accurately calculate $K_{D T}$ (and analogously $\mathrm{K}_{H D}$ and $\mathrm{K}_{H T}$ ) we must account for this ratio by multiplying $\mathrm{Eq}$. (13) by the rotational correction $\mathrm{K}_{\mathrm{DT}}$ (rot) as given in:

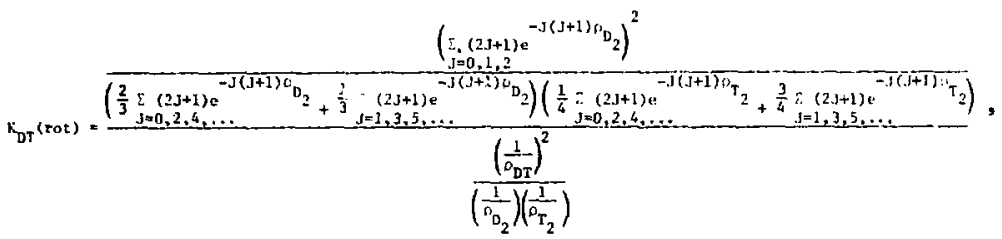


where $1 / \rho_{1}$ is the classical rotational partition function. Note that the symmetry-number factor is completely contained in the numeracor. Therefore when applying this correction, the symmetry-number ratios should be divided out of the uncorrected " $\mathrm{DT}$.

\section{QUALITATIVE IMPLICATIONS OF THE THEORY}

IF classical mechanics is employed to evaluate the partition function: ratio for isotopic molecules, one obtains ${ }^{1,6}$ those ratios as

$$
\frac{z_{\mathrm{DT}}^{0}}{\mathrm{z}_{\mathrm{D}}^{\mathrm{o}}}=\frac{\sigma_{\mathrm{D}_{2}}}{\sigma_{\mathrm{DT}}}\left(\frac{\mathrm{m}_{\mathrm{T}}}{\mathrm{m}_{\mathrm{D}}}\right)^{3 / 2} \text { and } \frac{\mathrm{z}_{\mathrm{T}}^{\circ}}{\mathrm{z}_{\mathrm{DT}}^{0}}=\frac{\sigma_{\mathrm{DT}}}{\sigma_{\mathrm{T}}}\left(\frac{\mathrm{m}_{\mathrm{T}}}{\mathrm{m}_{\mathrm{D}}}\right)^{3 / 2} \text {. }
$$

Therefore, Eq. (13) becomes

$$
k_{\mathrm{DT}}=\frac{\sigma_{\mathrm{D}_{2}}}{\sigma_{\mathrm{DT}}}\left(\frac{\mathrm{m}_{\mathrm{T}}}{m_{\mathrm{D}}}\right)^{3 / 2} / \frac{\sigma_{\mathrm{DT}}}{\sigma_{\mathrm{T}_{2}}}\left(\frac{m_{\mathrm{T}}}{\mathrm{m}_{\mathrm{D}}}\right)^{3 / 2}=\frac{\sigma_{\mathrm{D}_{2}{ }{ }_{\mathrm{T}}}}{\left(\sigma_{\mathrm{DT}}\right)^{2}}=\frac{(2)(2)}{1}=4 .
$$

Simflai equations can be wrtten for the other self-exchange reactions. We would obtain this same value if we assume a random distribution of the deuterium and tritium atoms among the hydrogenic molecules; i.e., there is just one way to form $D_{2}$ and $T_{2}$ from their atoms, but there are two ways to form DT. Therefore $\mathrm{K}_{\mathrm{DT}}$ would be

$$
K_{\mathrm{DT}}=\frac{(2)^{2}}{(1)(1)}=4
$$

The fact that doviations from this value of $\mathrm{K}_{\mathrm{DT}}$ are observed in these reactlons (except at high temperatures) indicates that classical mechanics is inadequate to describe these systems. The quantum mechanical treatment shows that the cuantum effect basically resides in the molecular vibrations. In particliar, the zero-point energy term - the exp[h $\left.v_{f} / 2 k T\right]$ term in Eg. (18) - makes the largest contribution to the equilibrium constant, ${ }^{1}$ especially at low temperatures.

Figure 1 shows the potential energy as a function of interatomic distance between the two atoms of a dlatomic molecule. When the atoms are far apart, they are independent of each other. As they are brought tugeth.., they are attracted to one another and so form a bund, which is represented by an energy 
level of the potential well. The term $x_{\mathrm{e}}$ is the equilibrium bond length of the diatomic molecule. If the atoms are pushed together to distances less than $r_{e}$, the potential rises sharply because of the repulsion energy. According to quantum theory, the vibrating molecule cannot assume fust any energy on the continuous curve shown in Fig. 1 . It is restricted to discrete energy levels, the lowest of these being the zero-point energy, $E_{O}(i)$ where $i$ indicates the isotopic form of the molecule. The zero-point energy, which is the vibrational energy contained by the molecule at absolute zero, is given by the expression

$$
E_{0}^{\circ}=\frac{1}{2} h \nu .
$$

The vibrational frequency, $v$, equals $1 / 2 \pi(k / \mu)^{1 / 2}$, where $k$ is the furce cunstant and $\mu$ is the reduced mass $m_{A} m_{B} f\left(m_{A}+m_{B}\right)-A$ and $B$ are hydrogen atoms. The force constant $\mathrm{j} . \mathrm{s}$ related to the curvature of the porential well in Fig. 1 , and is the same for all isotoplc species within the Born-0ppenheimer approximation.

Since $E_{0}^{O}$ depends on $V$, which in turn is an inverse function of mass, the zero-point energies for the isotopic hydrogen spectes will dj.fier from each other. Tritium, with the smallest value of $1 / \sqrt{\mu}$, will have the lowest zero-point energy. These levels are illustrated In Fig. 1. $E_{H}, E_{D}$, and

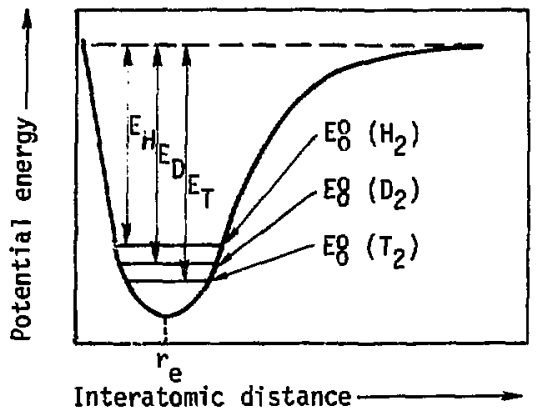

Fig. 1 Curve relating potential energy and interatomic distance. $E_{0}^{0}$ is the zero-point energy of the denoted molecule; $\mathrm{E}$ is the dissociation energy. The equilibrium bond length is labeled $r_{e}$.
$E_{T}$ represent the energies necessary to dissociate the molecules $\mathrm{H}_{2}, \mathrm{D}_{2}$, and $\mathrm{T}_{2}$. Since more energy is required to dissoclate the tritiun molecules, they are the most stable of the isotopic hydrogens.

The reduced masses 13 and the zero-point energtes (calculated from Ref. 12) of hydrogen's isotonic molecules are given in Table 2 . In Fig. 2, a plot of $E_{0}^{o}$ vs $1 / \sqrt{\mu}$ shows a linear relationship, expected from theory. The function $1 / \sqrt{\mu}$ would be a good function to corralate properties that are dependent on frequency of vibration. 
Table 2. Reduced mass and zero-point energy.

\begin{tabular}{cccc}
\hline Isotopic molecule & Reduced mess $\mu$ & $1 / \sqrt{\mu}$ & E, KJ/mole \\
\hline $\mathrm{H}_{2}$ & 0.5041 & 1.408 & 25.930 \\
$\mathrm{HD}$ & 0.6719 & 1.220 & 22.544 \\
$\mathrm{HT}$ & 0.7556 & 1.150 & 21.314 \\
$\mathrm{D}_{2}$ & 1.0074 & 0.996 & 18.458 \\
$\mathrm{DT}_{\mathrm{O}}$ & $1.208^{*}$ & 0.910 & 16.901 \\
$\mathrm{~T}_{2}$ & 1.5085 & 0.814 & 15.140 \\
\hline
\end{tabular}

"Omitted from Herzberg (Ref. 13).

The rule of the geometric mean ${ }^{14}$ states that the value of the equilibrium constant should nearly equal the classically calculated value, for isotoplc self-exchange reactions. The rule is exact at high temperature, as shown by Bigeleisen ${ }^{14}$ from the theory. One way of rationalizing this rule is to realize that even though there is an isotopic effect on both ratios of partition

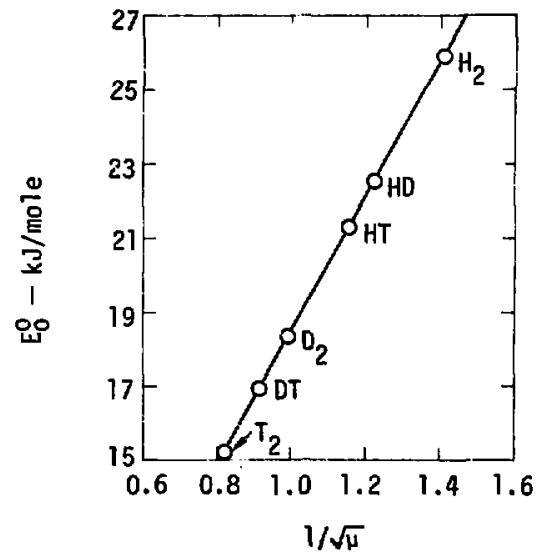

Fig. 2 Plot of $E_{O}^{O}$ vs $1 / \sqrt{\mu}$. functions in the expression for the equilibrium constant (see Eq. (13)), the two effects are in opposing directions and nearly cancel when the product is taken.

Wol fsberg ${ }^{1}$ has discussed the high- and low-temperature limits of isotopic equilibrium constants as a function of temperature. At low temperatures, the $\left(1-e^{-u 1}\right)$ terms in Eq. (18) equal one, so the equilibrium constant as given by Eq. (13) has the form

$$
\mathrm{K}_{\mathrm{DT}}=A \mathrm{e}^{\mathrm{B} / \mathrm{t}}
$$


where A reflects the products of frequencies and symmetry numbers, and $B$ is the appropriate zero-point energy difference. For the isotoplc exchange reactions of hydrogen, A should be close to the classical value of four, and the exponential term therefore contains the isotope effect. At absolute zero, the value ${ }^{5}$ of $K_{D T}$ is zero. This is because the zero-point energy sum for the pure species is less than twice the zero-point energy of the mixed species.

At high temperatures, the

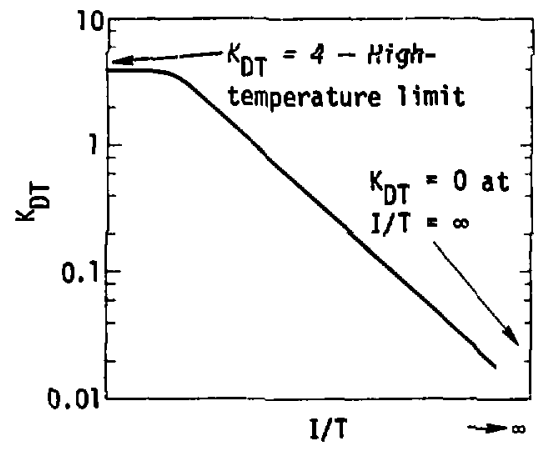

Fig. 3. Form of $1 \mathrm{n} \mathrm{K}_{\mathrm{DT}}$ vs $1 / \mathrm{T}$ from

Eqs. (31) and (32). equilibrium constant will have the form $^{1}$

$$
\mathrm{K}_{\mathrm{DT}}=4+\frac{\mathrm{C}}{\mathrm{T}^{2}}
$$

where $C$ is a constant and must be negative. The high-temperature limit is the classical value of four. Using Eqs. (31) and (32) for the extreme cases, we can predict the form of in $K_{D T}$ vs 1/T. This plot is shown In Fig. 3.

\section{Survey of the Literature for $K_{H D}, K_{H T}$, and $K_{D T}$}

The first reference to deuterium in the iiterature is by Urey et al. ${ }^{15}$ in 1932, and the first reference to tritium is by Lozier et al. ${ }^{16}$ in 1934 . We liave surveyed the literature from these early papers through the July-December 1975 Chemfcal Abstracts Indices for references to the isotopic exchange eguilibrium constants. The primary modern references found are a series of both theoretical calculations and experimental results by Jones. $17,18,19$ in addition to papers that explicitly report the values of equilibrium constants, there are papers that report free energy functions, from which the equllibrium constants can be calculated (see Ref, 12 for an example). We have not included these in our compilation of the data, especially since the theoretical calculations from many sources agree with one another. 
The experimental data found for $\mathrm{K}_{\mathrm{HD}}$ are given in Table 3. In addition, all of the values of $\mathrm{K}_{\mathrm{HD}}$ reported in Jones' theoretical paper ${ }^{18}$ are included in this table. Most of the points at low temperatures (large values of $1 / \mathrm{T}$ ) fall on a straight line (see Fig, 4). We have fitted the points on the line between $T=50$ and $T=300$ with a straight line by the method of least squares. The equation for the line is:

$$
\ln K_{H D}=\frac{-53.22}{T}+1.348 ; \text { or } K_{H D}=3.850 e^{-53.22 / T}
$$

In Tuble 4, the values of $K_{H D}$ we estimated using Eq. (33) are compared with the experimental and accurately calculated values at those temperatures.

Since, as shown in Table 4, the error in using Eq. (33) is small, it can ire used tis estimate the equilibrlum constant in the temperature interval specified with an accuracy of a few percent. Note that the pre-exponential

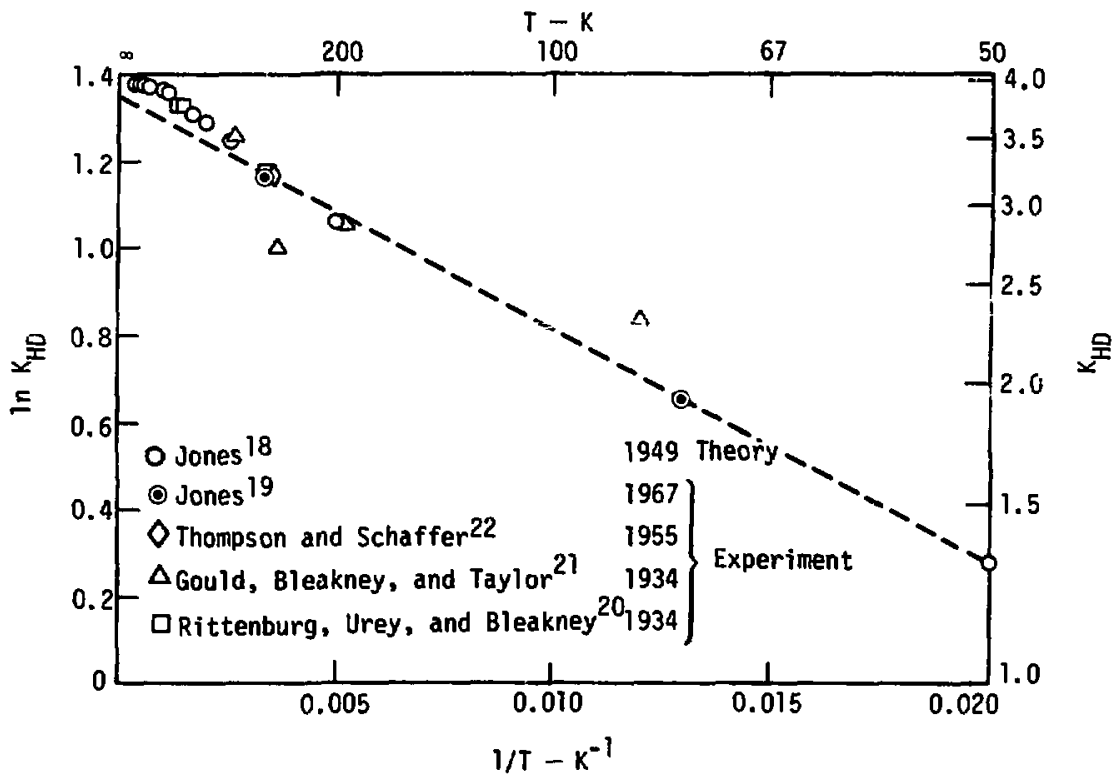

Fig. 4 plot of in K vs $1 / T$. 
Table 3. Comparison of the various experimental (ex) and theoretical (th) values of $\mathrm{K}_{\mathrm{HD}}$.

\begin{tabular}{|c|c|c|c|c|c|c|c|c|c|c|}
\hline \multirow{2}{*}{$\begin{array}{c}\text { Temperature, } \\
\text { K }\end{array}$} & \multicolumn{2}{|c|}{$\begin{array}{l}\text { Rictenberg. } \\
\text { ex a al. } .^{20} \\
\text { (193: })\end{array}$} & \multicolumn{2}{|c|}{$\begin{array}{l}\text { Gould } \\
\text { eE } \text { al. }^{211} \\
(1934)\end{array}$} & \multirow{2}{*}{$\begin{array}{l}\begin{array}{l}\text { Urey } \\
\text { (1947) }\end{array} \\
K_{E h}\end{array}$} & \multirow{2}{*}{$\frac{\begin{array}{c}\text { Jones }^{18} \\
(1949)\end{array}}{k_{t h}}$} & \multirow{2}{*}{$\begin{array}{c}\begin{array}{c}\text { Thompson } \\
\text { Schaef fer } \\
\text { (1955) }\end{array} \\
\frac{k_{\text {ex }}}{25}\end{array}$} & \multirow{2}{*}{$\frac{\begin{array}{c}\text { Jones }^{19} \\
(1967)\end{array}}{K_{\text {ex }}}$} & \multirow{2}{*}{ 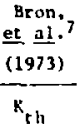 } & \multirow{2}{*}{$\begin{array}{l}\begin{array}{l}\text { Bron } \\
\text { Paul } \\
(1974) \\
(197)\end{array} \\
K_{t h}\end{array}$} \\
\hline & $k_{e x}$ & $k_{c h}$ & $k_{\mathrm{ex}}$ & $k_{t h}$ & & & & & & \\
\hline so & & & & & & 1.33 & & & & \\
\hline 76.7 & & & & & & & & 1.93 & & \\
\hline 83 & & & 2.3 & 2.2 & & & & & & \\
\hline 100 & & & & & & 2.26 & & & & \\
\hline 195 & & & 2.88 & 2.92 & & & & & & \\
\hline 200 & & & & & & 2.90 & & & 2.899 & 2.898 \\
\hline 273 & & & 3.18 & 3.19 & 3.18 & & & & & \\
\hline 293 & & & & & & & $\begin{array}{r}3.23 \\
\pm 0.07\end{array}$ & & & \\
\hline 298.1 & 3.28 & 3.28 & & & 3.25 & 3.26 & & & & \\
\hline 299 & & & & & & & & 3.27 & & \\
\hline 300 & & & & & & 3.26 & & & 3.264 & 3.264 \\
\hline 383 & & & 3.53 & 3.46 & & & & & & \\
\hline 400 & & & & & 3.48 & 3.48 & & & & \\
\hline 500 & & & & & 3.62 & 3.62 & & & & \\
\hline 600 & & & & & 3.72 & 3.72 & & & 3.721 & 3.720 \\
\hline 670 & 3.78 & 3.73 & & & & & & & & \\
\hline 700 & & & & & & 3.78 & & & & \\
\hline 741 & 3.75 & 3.82 & & & & & & & & \\
\hline 800 & & & & & & 3.83 & & & & \\
\hline 900 & & & & & & 3.87 & & & & \\
\hline 1000 & & & & & & 3,90 & & & & \\
\hline 1250 & & & & & & 3.94 & & & & \\
\hline 1500 & & & & & & 3.96 & & & & \\
\hline 2000 & & & & & & 3.97 & & & & \\
\hline 2500 & & & & & & 3.97 & & & & \\
\hline
\end{tabular}



Table 4. Comparison of estimated and calculated values of $K_{H D}(T=50$ to
$T=300 K)$.

\begin{tabular}{cccc}
\hline$T, K$ & $\begin{array}{c}\text { Estimated } K_{H D} \\
\text { Erom Eq. (33) }\end{array}$ & $\begin{array}{c}\text { Calculated } K_{H D} \\
\text { (from rable 3) }\end{array}$ & \% Error \\
\hline 50 & 1.33 & 1.33 & 0.0 \\
76.7 & 1.92 & $1.93^{*}$ & -0.5 \\
100.0 & 2.26 & 2.26 & 0.0 \\
200.0 & 2.95 & 2.90 & +1.7 \\
293.0 & 3.21 & $3.23^{*}$ & -0.6 \\
300.0 & 3.22 & 3.26 & -1.2 \\
\hline
\end{tabular}

Experimental values.

term is nearly the classical value of four. Also, remember that the constant in the exponential represents the zero-point energy change for the equilibrium reaction.

The very earliest data by Urey, et al. ${ }^{20}$ which was published in 1934 , agrees well with recent theory $7,18,23$ and experiment. 20 This is in marked contrast to other isotopic systems, in which recent experiments and theory have changed the values of the equilibrium constants (see Wolfsberg's discussion of the equilibrium constant for water in Ref. 1). On the other hand, the 1934 data by Gould, et al. ${ }^{21}$ has two points (at $83 \mathrm{~K}$ and $273 \mathrm{~K}$ ) that are not on the line in Fig. 4, which makes these data suspect.

The theoretical calculations of $\mathrm{K}_{\mathrm{HD}}$ by Jones were made by direct summation over rotational and vibrational states rather than by the method of Bigeleisen and Mayer. ${ }^{6}$ The value of $K_{H D}$ from the work of Thompson and Schaeffer ${ }^{22}$ is inreresting, since they used catalysis by $\alpha$ particles and 2-MeV electrons as well as chemical catalysts. They showed that the value of the thermodynamic equilibrium constant was the same no matter what phenomenon was used to bring about this enuilibration. The experimental work of Jones in $1967^{19} \mathrm{nicely}$ confirmed his earlier theoretical calculations.

In 1973 , Wolfsbers and co-workers ${ }^{7}$ recalculated the partition function ratios for the 1sotopic hydrogens, making a real effort to include all of the relevant corrections to the simple theory. As Table 3 shows, the earlier calculations of Jones agree very well with the very precise calculations of Wolfsberg. Bron and Paul ${ }^{23}$ report a recent calculation of the partition 
function ratios obtained by a direct sumation method, which also agrees well with Wolfsberg, et al.

Note that the temperature dependence of $\mathrm{ln} \mathrm{K}$, as shown in $\mathrm{Fig} .3$, is as predicted by Eqs. 31 and 32 . At high temperatures, $K_{H D}$ approaches the classical limit of four. The maximum value of $K_{H D} \simeq 3.98$ at $T=2000 k$, and subsequent decline of $\mathrm{K}_{\mathrm{HD}}$ at higher temperatures predicted by Murphy ${ }^{24}$ is contrary to modern theory and is therefore probably incorrect.

\section{THE EQUILIBRIUM CONSTANT $\mathrm{K}_{\mathrm{HT}}$}

The values for $\mathrm{K}_{\mathrm{KT}}$ that we found in the 11terature are given in iable 5 . In addition, all of the experimental points, plus the theoretical points calculated by Jones ${ }^{17}$ are plotted as $1 \mathrm{n} \mathrm{K}_{\mathrm{hI}}$ vs $1 / \mathrm{T}$ in Fig. 5 . As $1 \mathrm{~s}$ seen, the points in the temperature range from 50-300 $\mathrm{K}$ fall on a straight line with one exception. The points in this temperature range have been fitted with a

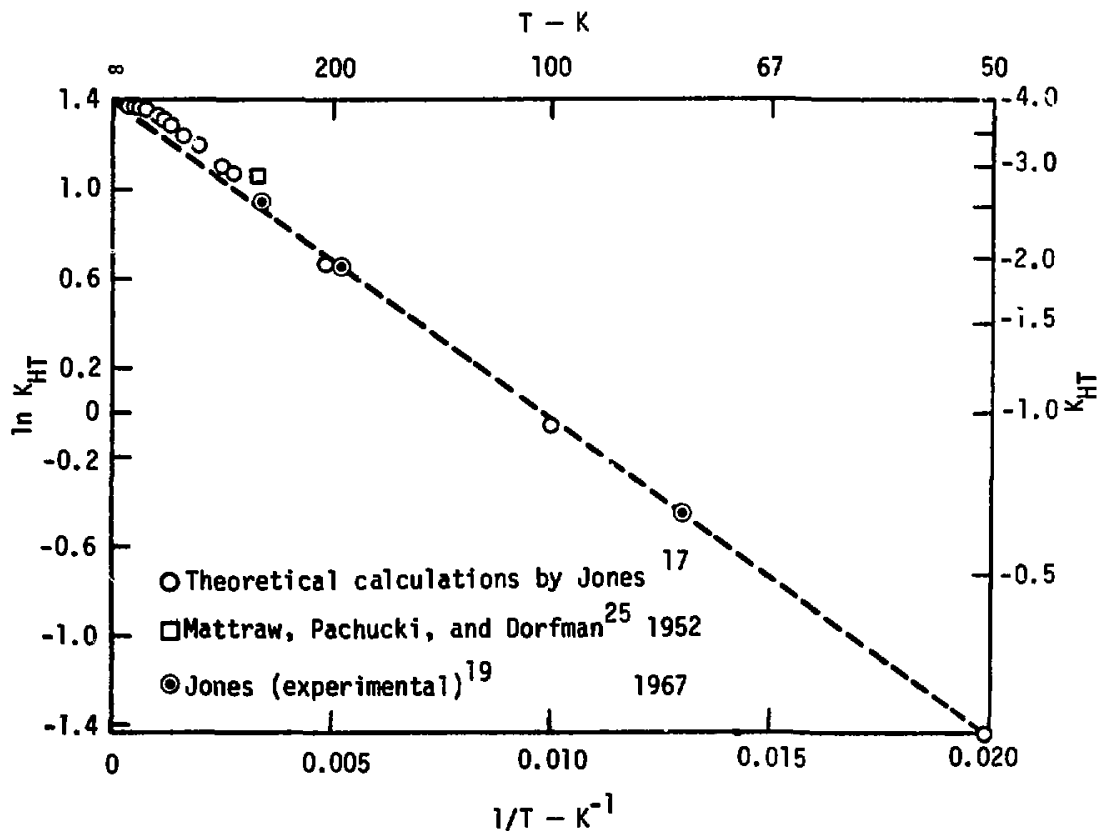

Fig. 5 Plot of in $K_{H T}$ vs $1 / T$. 
Table 5. Comparison of the various experimental (ax) and theoretical (th) values of $\mathrm{k}_{\mathrm{HT}}$.

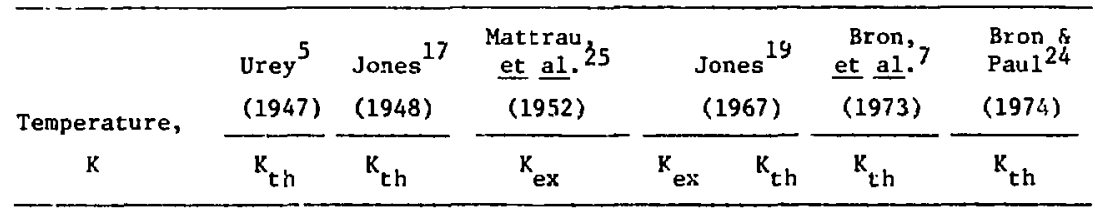

50

76.7

100

192

200

273.1

298. 1

299

300

400

500

600

700

800

900

1000

1250

1500

2000

2500
0.242

$$
\begin{array}{rr}
0.69 & 0.63 \\
\pm 0.02 & \pm 0.02
\end{array}
$$

0.947

$$
\begin{array}{ll}
1.92 & 1.915 \\
\pm 0.014
\end{array}
$$

$$
1.948
$$

$$
2.42
$$

$$
2.56
$$

2.57

$$
\begin{array}{r}
2.87 \\
\pm 0.06
\end{array}
$$$$
\begin{array}{lll}
2.58 & 2.575 \quad 2.572
\end{array}
$$
$\pm 0.014$

2. 58

$2.97 \quad 2.99$

$3.24 \quad 3.26$

$3.44 \quad 3.45$

3.59

3.68

3.76

3.81

3.90

3.94

3.98

3.99

* This number has been discredited In the literature. 
stralght line by the method of least squares. The equation for the line 1s:

$$
\ln \mathrm{K}_{\mathrm{HT}}=-\frac{140.86}{\mathrm{~T}}+1.385 ; \text { or } \mathrm{K}_{\mathrm{HT}}=3.995 \mathrm{e}^{-140.86 / \mathrm{T}} \text {. }
$$

In Table 6 the values of $\mathrm{K}_{\mathrm{HT}}$ estimated from Eq. (34) are compared with the experimental and accurately calculated values as a function of temperature.

Table 6. Comparison of estimated and calculated values of $K_{H T}(50-300 \mathrm{~K})$.

\begin{tabular}{cccc}
\hline T, K & $\begin{array}{c}\text { Estimated } \mathrm{K}_{\mathrm{HT}} \\
\text { (from Eq. }(34))\end{array}$ & $\begin{array}{c}\text { Calculated KT } \\
\text { (Erom Table 5) }\end{array}$ & $\%$ Error \\
\hline 50 & 0.239 & 0.242 & -1.2 \\
76.7 & 0.64 & 0.63 & 0.0 \\
100 & 0.977 & 0.947 & +3.2 \\
192 & 1.92 & 1.92 & 0.0 \\
200 & 1.98 & 1.95 & +1.5 \\
300 & 2.50 & 2.58 & -2.7 \\
\hline
\end{tabular}

The largest errors obtained from using Eq. 34 are on the order of $3 \%$. Therefore, Eq. (34) can be used to estimate $K_{\text {HT }}$ with an error of $3 \%$ or less. Note again that the pre-exponential term of $\mathrm{K}_{\mathrm{HT}}$ is approximately the classical value of four, that the constant in the exponential is proportional to the zero-point energy change for the equilibrium reaction, and that the shape of the curve formed by the points in Fig. 5 is as predicted by Eq. (31),

The earliest theoretical calculation of $\mathrm{K}_{\mathrm{HT}}$ by Urey ${ }^{5}$ in 1947 and those of Jones $^{17}$ In 1948 agree very well with the most recent calculations, ${ }^{2,23}$ which Include latest possible spectroscopic data and corrections. The theory also agrees very well with the experimental data of Jones. 19 The experimental data of Mattraw, et al., ${ }^{25}$ do not agree with the theory. These workers equilibrated the hydrogen-tritium mixtures using the $B$ ray from the tritium. The work of Jones $^{19}$ suggests that it may have been impuritles in the gaseous mixture that caused the discrepancy. Thompson and Schaeffer ${ }^{22}$ showed that there was no difference in $\mathrm{K}_{\mathrm{HT}}$ when the mixtures were equilibrated by radiation flelds or chemical catalysts. In view of their findings, we belleve that the $K_{H T}$ reported by Mattraw, et al. ${ }^{25}$ is erroneous. 
THE EQUILIBRIUR CONSTANT K $\mathrm{D}^{\prime \prime}$

The values of $K_{\partial T}$ from the literature are shown in Table 7. Also, the values of $K_{D T}$ calculated from spectroscopic data by Jones ${ }^{18}$ and his experimental measurements of $\mathrm{K}_{\mathrm{DT}} 19$ are plotted in Fig. 6 . It should be noted that Jones calculated a point at $25 \mathrm{~K}$ for this reaction only. It dees not $f i t$ on the linear $\mathrm{p} 1 \mathrm{nt}$ of $\ln \mathrm{K}_{\mathrm{DT}}$ vs $1 / \mathrm{T}$. This deviation from 11nearity is due to the rotational correction becoming signiffcant, as shown in the next sertion.

We have fitted the points in the temperature range 50-300 $\mathrm{K}$ with a straight line, using the least squares method. The equation for the line is:

$$
\ln K_{D T}=-\frac{22.72}{T}+1.421 ; \text { or } K_{D T}=4.141 \mathrm{e}^{-22.72 / \mathrm{T}} \text {. }
$$

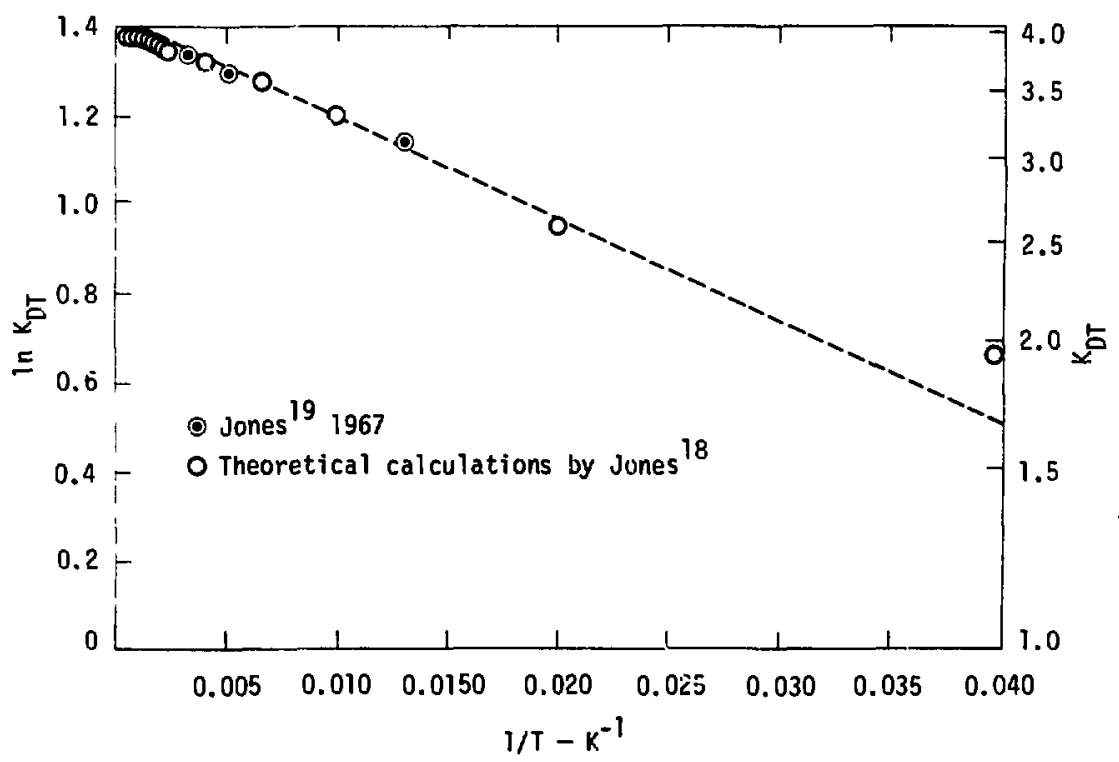

Fig. 6 Plot of $\ln K_{D T}$ vs $1 / T$. 
Table 7. Comparison of the various experimental (ex) and theoretical (th) values of $\mathrm{K}_{\mathrm{DT}}$.

\begin{tabular}{|c|c|c|c|c|c|c|}
\hline \multirow{2}{*}{$\begin{array}{c}\text { Temperature, } \\
\text { K }\end{array}$} & \multirow{2}{*}{$\begin{array}{l}\begin{array}{l}\text { Urey } \\
5 \\
(1947)\end{array} \\
K_{t h}\end{array}$} & \multirow{2}{*}{$\begin{array}{c}\text { Jones }^{18} \\
(1949) \\
K_{\text {th }}\end{array}$} & \multicolumn{2}{|c|}{$\begin{array}{c}\text { Jones }^{19} \\
(1967)\end{array}$} & \multirow{2}{*}{$\frac{\begin{array}{c}\text { Bron } \\
\text { et al }\end{array}}{(1973)}$} & \multirow{2}{*}{$\begin{array}{l}\text { Bron s } \\
\text { Paul23 } \\
(1974) \\
k_{\text {th }}\end{array}$} \\
\hline & & & $\mathrm{K}_{\mathrm{ex}}$ & $k_{t h}$ & & \\
\hline 25 & & 1.95 & & & & \\
\hline 50 & & 2.60 & & & & \\
\hline 76.7 & & & 3.12 & 3.11 & & \\
\hline 100 & & 3.32 & & & & \\
\hline 150 & & 3.57 & & & & \\
\hline 192 & & & 3.64 & 3.67 & & \\
\hline 200 & & 3.69 & & & 3.683 & 3.684 \\
\hline 250 & & 3.77 & & & & \\
\hline 273.1 & 3.79 & & & & & \\
\hline $298: 1$ & 3.82 & 3.82 & & & & \\
\hline 299 & & & 3.82 & 3.82 & 3.811 & $3 . \ell 11$ \\
\hline 300 & & 3.02 & & & & \\
\hline 400 & 3.88 & 3.88 & & & & \\
\hline 500 & 3.92 & 3.93 & & & & \\
\hline 600 & 3.94 & 3.96 & & & 3.942 & 3.942 \\
\hline 700 & & 3.97 & & & & \\
\hline 800 & & 3.98 & & & & \\
\hline 900 & & 3.98 & & & & \\
\hline 1000 & & 3.99 & & & & \\
\hline 2250 & & 4.00 & & & & \\
\hline 1500 & & 4.00 & & & & \\
\hline 2000 & & 4.00 & & & & \\
\hline 2500 & & 4.00 & & & & \\
\hline
\end{tabular}


The estimated values of $\mathrm{K}_{\mathrm{JT}}$, as calculated using $\mathrm{Eq}$. (35) and as compared with ، accurately calculated values, are given in Table 8 as a function of tumperature. The maximum error from this procedure was about $1 \%$, so Eq. (35) can be used to estimate $\mathrm{K}_{D T}$ wthin $1 \%$. Note that the pre-exponential term is larger than the classical value of four. This, of course, is due to the fact that the lincar relationship in Fig. 6 is above the high-temperature polnts. The cunstant in the exponential is proportional to the zero-point energy change for the equilibrium reaction.

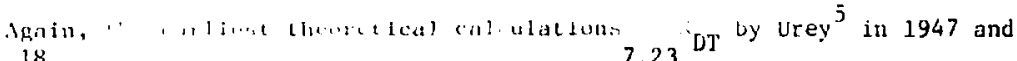
Iones 18 in 1249 agres very well with the latest 7,23 calculations and also with the experimental data of Jones. 19

Table 8. Comparison of estimated and calculated values of $\mathrm{K}_{\mathrm{DT}}(50-300 \mathrm{~K})$.

\begin{tabular}{|c|c|c|c|}
\hline$T, K$ & $\begin{array}{l}\text { Estimated } \mathrm{K}_{\mathrm{DT}} \\
\text { (from Eq. 35) }\end{array}$ & $\begin{array}{l}\text { Calculated }{ }^{\mathrm{DT}} \\
\text { (from Table } 7 \text { ) }\end{array}$ & $\%$ Error \\
\hline 50 & 2.63 & 2.60 & +1.1 \\
\hline 76.7 & 3.08 & $3.12^{*}$ & -1.3 \\
\hline 100 & 3.30 & 3.32 & -0.6 \\
\hline 150 & 3.56 & 3.57 & -0.2 \\
\hline 192 & 3.68 & $3.64^{k}$ & +1.1 \\
\hline 200 & 3.70 & 3.69 & +0.3 \\
\hline 250 & 3.78 & 3.77 & +0.3 \\
\hline 300 & 3.84 & $3.82^{*}$ & +0.5 \\
\hline
\end{tabular}

Experimental values.

\section{Calculation of $K_{H D}, K_{H T}$, and $K_{D T}$ at Temperatures Between 4.2 and $50 \mathrm{~K}$}

To compute the vibrational contribution to the equij.ibrium constant as given by Eq. (13), we have to obtain the vibrational frequency we for each molecule. The $\omega_{\mathrm{e}}$ value for hydrogen is $4395.24 \mathrm{~cm}^{-1}$. We calculate the isotopically independent force constant $k_{e}$ from the hydrogen $\omega_{e}$ value by solving for $k_{e}$ in the following equation:

$$
\omega_{e}=\frac{1}{2 \pi c} \sqrt{\frac{k_{e}}{\mu_{1}}} .
$$


Next, we calculate the $w_{e}$ values for each molecule by using $\mathrm{k}_{\mathrm{e}}$ and Eq. (36). The values of the reduced masses and the calculated vibrational frequencies are given in Table 9. This procedure is more accurate than using various published $\dot{ }_{\mathrm{e}}$ values or $\omega_{\mathrm{e}}$ values that are not 1sotopically independent. 26

To compute the rotational correction from Eq. (26), it is necessary to compute the $\mathrm{B}_{\mathrm{e}}$ values $(\mathrm{Eq} .(20))$ for each isotopic molecule. The constant $B_{e}$ is propoitional to $\mathrm{H}^{-1} \cdot 23$ Therefore the $B_{e}$ values are computed in the same way as the ' wlues: the hydrogen value of $\mathrm{B}_{e}=60.864 \mathrm{~cm}^{-1}$ (fron Ref. 27) is used to determine the proportionality constant $k$, and the $B_{e}$ values are found from $B_{e}=k^{-1}$. The results are given in Table 10 .

Using the above daca, we calculated $K_{H D}, K_{H T}$, and $K_{D T}$, as products of Eqs. (13) and (24), at various temperatures. The results are given in Iable 11. At higher temperatures, where comparison is posstble, our values of the equilibrium constants are compared with the theoretical values of Jones. 18 The agreement is good, within $1 \%$.

A semi-log plot of the values of $K_{H D}$, $K_{H T}$, and $K_{D T}$ versus $1 / T$ is shown in Fig. 7. Note that the plot of $K_{D T}$ versus $1 / T$ consists of two linear portions connected by an s-shaped region. This sransition region occurs at the temperatures where the rotational correction begins to become important. The curves for $K_{H D}$ and $K_{H T}$ will show the same behavior at higher temperatures.

Since the S-shaped curve occurs in the region of the triple polnt, which is the temperature range of interest, we have shown it more closely in Fig. 8. As is seen, in the temperature range 16.7 to $33.3 \mathrm{~K}$, the curve can be approximated by a straight line. The equation of this line from a least squares $f 1 t$ is

$$
K_{D T}=2.995 e^{-10.82 / T}
$$

We can check the accuracy of this equation by comparing the original points calculated from theory to the fitted points. This comparison is shown in Table 12. As is seen, the fitted equation gives results that are certainly as accurate as the calculations themselves. 
Table 9. Reduced masses and vibrational frequencies for the hydrogen isotopic molecules.

\begin{tabular}{ccc}
\hline Molecule & $\mu_{1}$ & $\omega_{\mathrm{e}}$ (calculated), $\mathrm{cm}^{-1}$ \\
$\mathrm{H}_{2}$ & 0.5041 & 4395.24 \\
$\mathrm{HD}$ & 0.6719 & 3807.05 \\
$\mathrm{HT}$ & 0.7556 & 3590.00 \\
$\mathrm{D}_{2}$ & 1.0074 & 3109.14 \\
$\mathrm{DT}$ & 1.208 & 2839.27 \\
$\mathrm{~T}_{2}$ & 1.5085 & 2540.78
\end{tabular}

Table 10. Reduced masses and rotational constants for the isotopic hydrogen molecules.

\begin{tabular}{cccc}
\hline Molecule & $\mu$ & $\mu^{-1}$ & $L_{\mathrm{e}}, \mathrm{cm}^{-1}$ \\
$\mathrm{H}_{2}$ & 0.5041 & 1.9837 & 60.86 \\
$\mathrm{HD}$ & 0.6719 & 1.4883 & 45.66 \\
$\mathrm{HT}$ & 0.7556 & 1.3235 & 40.61 \\
$\mathrm{D}_{2}$ & 1.0074 & 0.9927 & 30.46 \\
$\mathrm{DT}$ & 1.208 & 0.8278 & 25.40 \\
$\mathrm{~T}_{2}$ & 1.5085 & 0.6629 & 20.34 \\
\hline
\end{tabular}




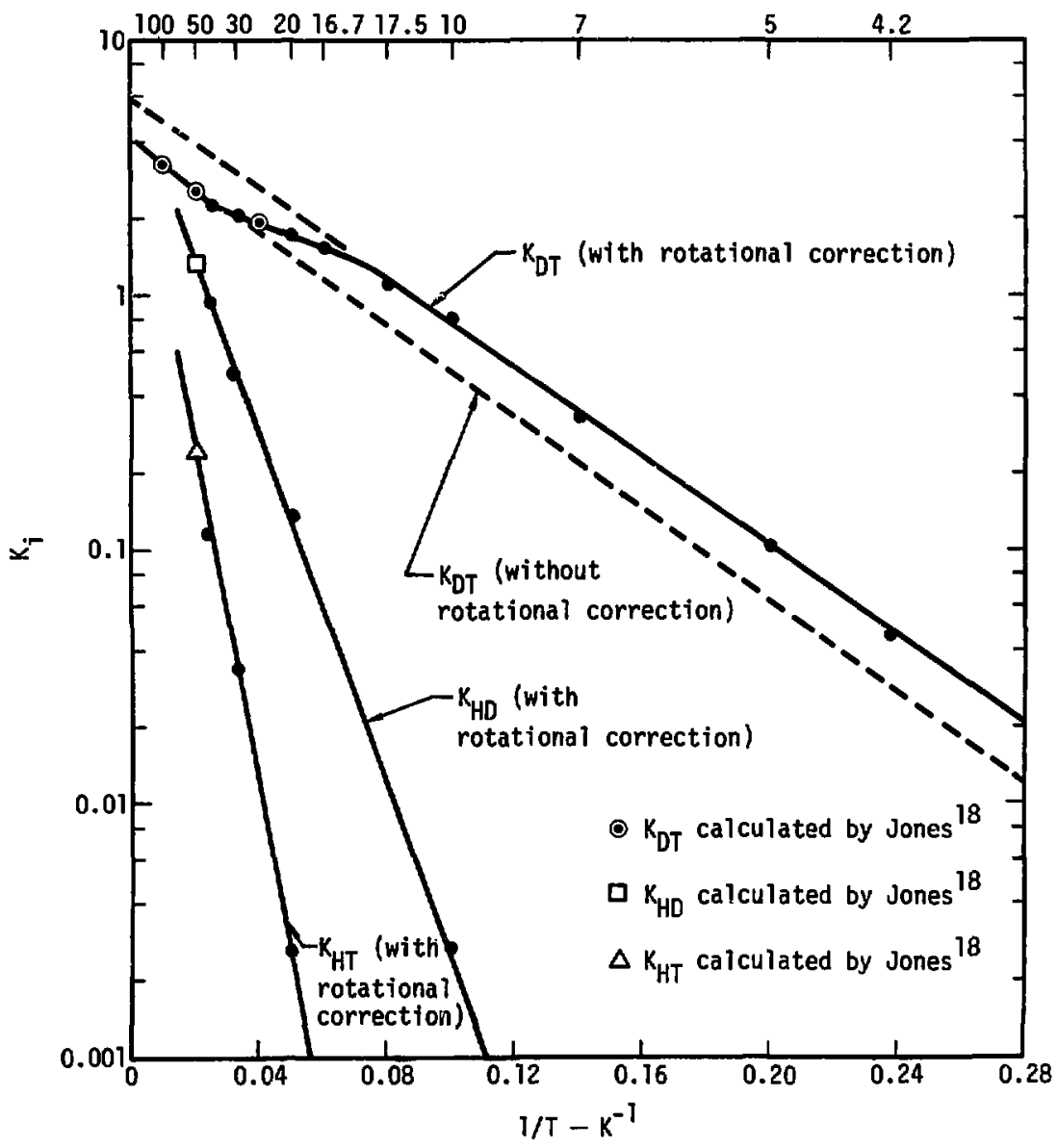

Fig. 7. Semi-log $\mathrm{plot}$ of $\mathrm{K}_{\mathrm{HD}}, \mathrm{K}_{\mathrm{HT}}$, and $\mathrm{K}_{\mathrm{DT}}$ as a function of $1 / \mathrm{T}$. 


$$
\mathrm{T}-\mathrm{K}
$$

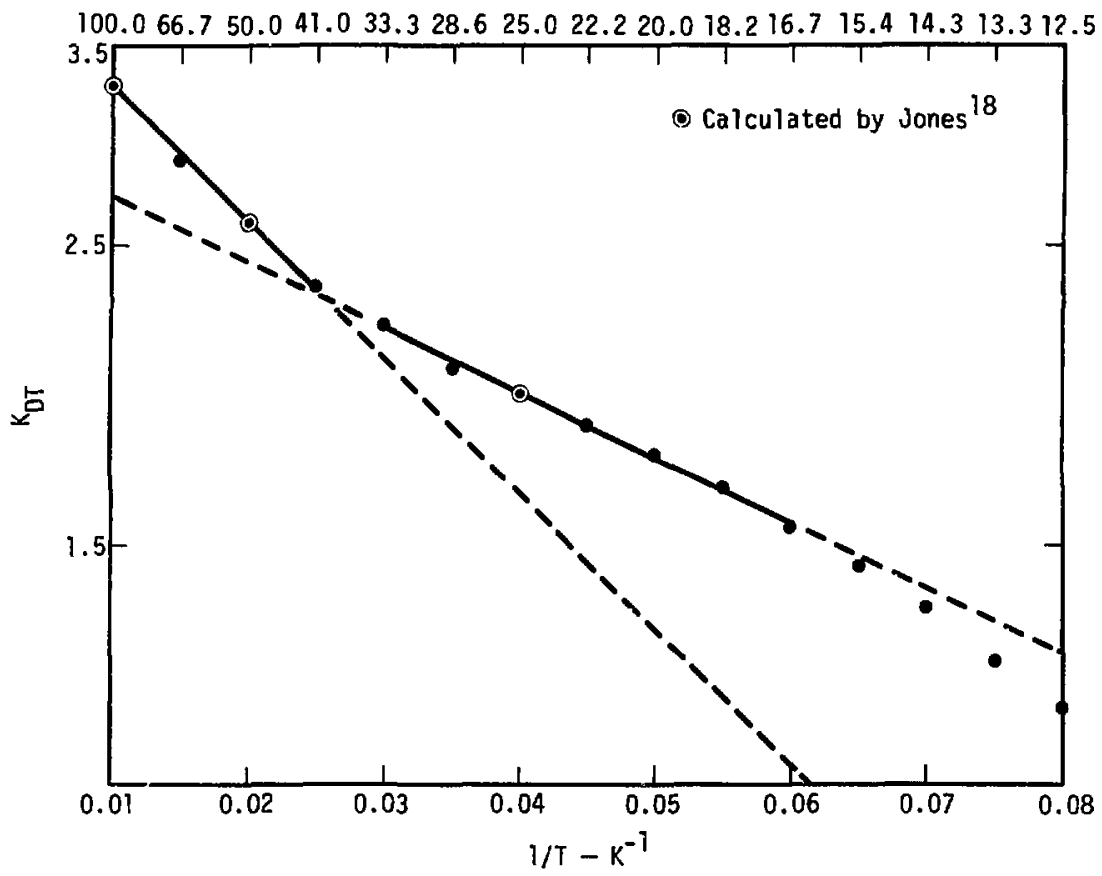

Fig. 8. Semi-log plot of $K_{D T}$ versus $1 / T$ in the temperature range 12.5 to
$100 \mathrm{~K}$.

The semi-log plot of $K_{D T}$ versus $1 / T$ in $1 \mathrm{~g}$. 7 was also fitted with a least squares plot in the temperature range 4.2 to $12.5 \mathrm{~K}$. The exponential equation of the resulting line is

$$
K_{D T}=5.924 \mathrm{e}^{-20.24 / \mathrm{T}} \text {. }
$$

In Table 13, values of $\mathrm{K}_{\mathrm{DT}}$ from Eq. (38) are compared with those originally calculated. The reproduction error is less than $3 \%$. 
Table 11. The values of $K_{H P}, K_{H T}$, and $K_{D T}$ as a function of temperature. Values in parentheses are those of Jones. 18

\begin{tabular}{|c|c|c|c|}
\hline $\mathbf{T}$ & $\mathrm{K}_{\mathrm{HD}}$ & $\mathrm{K}_{\mathrm{HT}}$ & $\mathrm{K}_{\mathrm{DT}}$ \\
\hline 4.2 & $4.90 \times 10^{-8}$ & $1.74 \times 10^{-17}$ & 0.0472 \\
\hline 5.0 & & & 0.104 \\
\hline 7.0 & & & 0.336 \\
\hline 10.0 & $2.67 \times 10^{-3}$ & $5.70 \times 10^{-7}$ & 0.795 \\
\hline 12.5 & & & 1.14 \\
\hline 13.3 & & & 1.24 \\
\hline 14.3 & & & 1.36 \\
\hline 15.4 & & & 1.45 \\
\hline 16.7 & & & 1.56 \\
\hline 18.2 & & & 1.66 \\
\hline 20.0 & 0.137 & $2.60 \times 10^{-3}$ & 1.75 \\
\hline 22.2 & & & 1.84 \\
\hline 25.0 & & & $1.93(1.95)$ \\
\hline 28.6 & & & 2.04 \\
\hline 30.0 & 0.500 & $3.38 \times 10^{-2}$ & 2.07 \\
\hline 33.3 & & & 2.18 \\
\hline 40.0 & 0.942 & 0.118 & 2.33 \\
\hline 50.0 & $1.34(1.33)$ & $0.244(0.242)$ & $2.57(2.60)$ \\
\hline 66.7 & & & 2.89 \\
\hline 100.0 & & & $3.29(3.32)$ \\
\hline
\end{tabular}

The semi-log plots for $\mathrm{K}_{\mathrm{HD}}$ and $\mathrm{K}_{\mathrm{HT}}$ in Fig. 7 were also fitted by the method of least squares with a straight line in the temperature range 4.2 to $50 \mathrm{~K}$. The resulting equations for these equilibrium constants are

$$
\mathrm{K}_{\mathrm{HD}}=6.785 \mathrm{e}^{-78.70 / \mathrm{T}} \text {, }
$$

and

$$
\mathrm{K}_{\mathrm{HT}}=10.22 \mathrm{e}^{-171.1 / \mathrm{T}} \text {. }
$$


iable 12. Comparison of calculated and fitted points for $K_{D T}$ in the temperature range 16.7 to $33.3 \mathrm{~K}$.

\begin{tabular}{|c|c|c|c|}
\hline $\mathrm{T}$ & $\begin{array}{l}\text { Est imated } K_{D T} \\
(\text { r rom kq. } 37 \text { ) }\end{array}$ & $\begin{array}{l}\text { Calculated } K_{D T} \\
\text { (irom kgs. } 13 \text { and } 24 \text { ) }\end{array}$ & * Error \\
\hline 16.7 & 1.57 & 1.56 & +0.5 \\
\hline 18.2 & 1.65 & 1.66 & -0.6 \\
\hline 20.0 & 1.74 & 1.75 & -0.6 \\
\hline 22.2 & 1.84 & 1.84 & 0.0 \\
\hline 25.0 & 1.44 & 1.93 & +0.5 \\
\hline 28.6 & 2.05 & 2.04 & +0.5 \\
\hline 30.0 & 2.09 & 2.07 & +0.9 \\
\hline 33.3 & 2.16 & 2.18 & -0.9 \\
\hline
\end{tabular}

Table 13. Comparison of the calculated and fisced polnts for $k_{D T}$ in the temperature range 4.2 to $12.5 \mathrm{~K}$.

\begin{tabular}{|c|c|c|c|}
\hline$T$ & $\begin{array}{l}\text { Est ima!ed } k_{\mathrm{DT}} \\
\text { (from Eq. } 38 \text { ) }\end{array}$ & $\begin{array}{l}\text { Calculated } k_{\mathrm{DT}} \\
\text { (from Eqs. } 13 \text { and 24) }\end{array}$ & $\%$ Error \\
\hline 4.2 & 0.0479 & 0.0472 & +1.5 \\
\hline 5.0 & 0.103 & 0.104 & -0.1 \\
\hline 7.0 & 0.329 & 0.336 & -2.1 \\
\hline 10.0 & 0.783 & 0.795 & -1.5 \\
\hline 12.5 & 1.17 & 1.14 & +2.6 \\
\hline
\end{tabular}


Table 14. Comparison of the calculated and fitted points for $\mathrm{K}_{\mathrm{H} \text { : }}$ and $\mathrm{K}_{\mathrm{HT}}$ in the temperature range 4.2 to $50 \mathrm{~K}$.

\begin{tabular}{|c|c|c|c|c|c|c|}
\hline$T$ & $\begin{array}{l}\text { Estimated } \\
\mathrm{K}_{\mathrm{HD}}(\text { from } \\
\text { Eq. (39)) }\end{array}$ & $\begin{array}{l}\text { Calculated } \\
\text { KHD (from } \\
\text { Eqs. (13) } \\
\text { and (24)) }\end{array}$ & $\%$ Error & $\begin{array}{l}\text { Est imatec' } \\
\text { KHT (from }_{\text {Eq. }}(40) \text { ) }\end{array}$ & $\begin{array}{l}\text { Calculated } \\
\mathrm{K}_{\mathrm{HT}} \text { (from } \\
\text { Eqs. (13) } \\
\text { and }(24) \text { ) }\end{array}$ & $\%$ Error \\
\hline 4.2 & $4.94 \times 10^{-8}$ & $4.90 \times 10^{-8}$ & +0.8 & $2.06 \times 10^{-17}$ & $1.74 \times 10^{-17}$ & +18.4 \\
\hline 10.0 & $2.59 \times 10^{-3}$ & $2.67 \times 10^{-3}$ & -3.0 & $3.78 \times 10^{-7}$ & $5.70 \cdot 10^{-7}$ & -33.7 \\
\hline 20.0 & 0.133 & 0.137 & -2.9 & $1.96 \times 10^{-3}$ & $2.60 \times 10^{-3}$ & -24.6 \\
\hline 30.0 & 0.492 & 0.500 & -1.6 & $3.40 \times 10^{-2}$ & $3.38 \times 10^{-2}$ & -0.6 \\
\hline 40.0 & 0.949 & 0.942 & +0.7 & 0.142 & 0.118 & +20.3 \\
\hline 50.0 & 1.41 & 1.34 & +5.2 & 0.333 & 0.244 & +36.5 \\
\hline
\end{tabular}

The values of these equilibrium constants range over many orders of magnitude, so Eqs. (39) and (40) are not as accurate as the equation for $K_{D T}$. This point is illustrated in Table 14 .

\section{Conclusions and Proposals for Future Work}

A review of the literature from the early 1930 's to December 1075 produced a number of theoretical and experimental values of the equilibrium constants for the isotopic self-exchange reactions of hydrogen. Generally, in the temperature range of 50 to $2500 \mathrm{~K}$, these calculations are in good agreement with each other and with experiment at the prescribed temperatures. The few experimental data points that do not agree with theory and other experimencs appear to be invalid. If the precise values of $\mathrm{K}_{\mathrm{HD}}, \mathrm{K}_{\mathrm{HT}}$, and $\mathrm{K}_{\mathrm{DT}}$ are desired in the temperature range of 220 to $600 \mathrm{~K}$, we suggest using the fitted equations of Bron, Chang, and Wolfsberg, ${ }^{7}$ or in the range 200 to $800 \mathrm{~K}$ the fitted equations of Bron and Paul. 24

We have used the partition function ratios from these two papers to derive expressions for the various equilibrium constants compared with earlier work in Tables 3, 4, and 7. So that others may use these equations, we report 
in Appendix $B$ the equations we derived from the partition function ratios of these two papers. We have fltted linear equations to the a raflable data for $K_{H D}, K_{H T}$, and $K_{D T}$ in the temperature range 50 to $300 \mathrm{~K}$. These equations are more convenient to use if errors of the order of $1-3 \%$ are acceptable. We have calculated the values of $\mathrm{K}_{\mathrm{HD}}, \mathrm{K}_{\mathrm{HT}}$, and $\mathrm{K}_{\mathrm{DT}}$ at varlous temperatures in the range 4.2 to $50 \mathrm{~K}$ using the Bigelefsen-Mayer theory including rotational correction. We feel that these calculations are accurate to $1 \%$. Ma: Wolfsberg and his co-workers at the University of Caljfornia at Irvine are planning to make detafled computer calculations of $\mathrm{K}_{\mathrm{HD}}, \mathrm{K}_{\mathrm{HT}}$, and $\mathrm{K}_{\mathrm{DT}}$ incorporating all of the significant correctlons in the temperatur: range 0 to $200 \mathrm{~K}$, which will provide a check on our calculations. We are presently building a cryostatquadrupole mass filter system to measure these equilibrium constants in the temperature range 4.2 to $25 \mathrm{~K}$.

\section{Acknowledgments}

We wculd like to thank the Division of Physical Research, Energy Research and Development Administration, for its support of bastc DT studies at cryogenic temperatures. We also appreclate suggestions from Jacob Bigeleisen and Max Wolfsberg on the theory of isotopic exchange reactions. 


\section{Appendix A \\ Sample Calculation of $K_{D T}$ at $25 \mathrm{~K}$}

Data for calculation

$\begin{array}{lllll}\text { Molecule } & \omega_{\mathrm{e}} \cdot \mathrm{cm}^{-1} & \mathrm{u}_{\mathrm{i}} & \mathrm{B}_{\mathrm{e}}, \mathrm{cm}^{-1} & \rho \\ \mathrm{D}_{2} & 3109.14 & 178.96 & 30.46 & 1.753 \\ \mathrm{DT} & 2839.27 & 165.143 & 25.40 & 1.462 \\ \mathrm{~T}_{2} & 2540.78 & 146.25 & 20.34 & 1.171\end{array}$

Frot. Blgeleisen and Mayer: ${ }^{6}$

$$
\frac{\sigma}{\sigma^{\prime}} f=\frac{u_{i}}{u_{i}^{\prime}} \exp \left(\frac{u_{i}^{\prime}-u_{1}}{2}\right) \frac{\left(1-e^{-u_{i}^{\prime}}\right)}{\left(1-e^{-u_{1}}\right)} \begin{aligned}
& \text { (Prime signifles lighter molecule; } \\
& \sigma^{\prime} \text { are symmetry numbers.) }
\end{aligned}
$$

$\frac{1}{2} \mathrm{f} \frac{\mathrm{DT}}{\mathrm{D}_{2}}=\frac{163.43}{178.96} \exp \left(\frac{178.96-163.43}{2}\right) \frac{\left(1-\mathrm{e}^{-178.96}\right)}{\left(1-\mathrm{e}^{-163.43}\right)}=0.913 \cdot 2350.66 \frac{(1-0.000)}{(1-0.009)}$

$=2152, \quad \mathrm{E} \frac{\mathrm{DT}}{\mathrm{D}_{2}}=2(2152)$

$\frac{2}{1} \mathrm{f} \frac{\mathrm{T}_{2}}{\mathrm{DT}}=\frac{146.25}{163.43} \exp \left(\frac{163.43-146.25}{2}\right) \frac{\left(1-\mathrm{e}^{-163.43}\right)}{\left(1-\mathrm{e}^{-146.25}\right)} 0.895 \cdot 5377.61$

$=4813, \quad f \frac{T_{2}}{D T}=1 / 2(4813)$

$\mathrm{K}_{\mathrm{DT}}$ (uncorrected) $=\mathrm{f} \frac{\mathrm{DT}}{\mathrm{D}_{2}} / \mathrm{f} \frac{\mathrm{T}_{2}}{\mathrm{DT}}=4 \frac{(2152)}{(4813)}=4\left(0.447_{1}\right)=1.78_{9}$

$\mathrm{Z}_{\mathrm{QM}}^{\mathrm{D}_{2}}(\mathrm{r})=0.6667\left[1+5 \mathrm{e}^{-6(1.753)}\right]+0.3333\left[3 \mathrm{e}^{-2(1.753)}+7 \mathrm{e}^{12(1.753)}\right]$

$=0.6968$

$\mathrm{z}_{\mathrm{QM}}^{\mathrm{DT}}(\mathrm{r})=1+3 \mathrm{e}^{-2(1.462)}+5 \mathrm{e}^{-6(1.462)}=1.1693$ 


$$
\begin{aligned}
\mathrm{Z}_{\mathrm{QM}}^{\mathrm{T}}(\mathrm{r}) & =0.25\left[1+5 \mathrm{e}^{-6(1.171)}\right]+0.75\left[3 \mathrm{e}^{-2(1.171)}+7 \mathrm{e}^{-12(1.171)}\right] \\
& =0.4674 \\
\mathrm{~K}_{\mathrm{DT}}(\mathrm{rot}) & =\frac{\frac{(0.6968)(0.4674)}{\left(\frac{1}{1.462}\right)^{2}}=\frac{4.1452}{(0.9604)}=4.316}{\left(\frac{1}{1.753}\right)\left(\frac{1}{1.171}\right)}
\end{aligned}
$$

Since the symmetry-number factor is completely contained in the numerator of the equation for $K_{D T}$ (rot), the factor is divided out of $K_{D T}$ (uncorrected) in calculating $\mathrm{K}_{\mathrm{DT}}$ (corrected):

$$
\begin{aligned}
K_{D T}(\text { corrected }) & =\frac{K_{D T} \text { (uncorrected) }}{\text { symetry factor }} \cdot K_{D T}(\text { rot }) \\
& =(0.4471)(4.316)=1.93\left(\text { Jones }^{18}=1.95\right) .
\end{aligned}
$$




\begin{tabular}{|c|c|c|c|c|}
\hline Authors & Ref. & Equation & $\begin{array}{l}\text { Valtd } \\
\text { temperature } \\
\text { range }\end{array}$ & $\begin{array}{c}\text { Value } \\
\text { of } t\end{array}$ \\
\hline $\begin{array}{l}\text { Bron, } \\
\text { Chang, } \\
\text { Wolfsberg }\end{array}$ & 7 & $\begin{array}{l}\ln \left(K_{\mathrm{HD}} / 4\right)=0.0364 .3-0.15868(\tau) \\
-0.16622\left(\tau^{2}\right)+0.10780\left(\tau^{3}\right) \\
-0.02177\left(\tau^{4}\right)\end{array}$ & $220-600 k$ & $300 / T$ \\
\hline $\begin{array}{l}\text { Bron, } \\
\text { Chang, } \\
\text { Wolfsberg }\end{array}$ & 7 & $\begin{array}{l}\ln \left(K_{\mathrm{HT}} / 4\right)=0.09122-0.36356(\tau)= \\
-0.33119\left(\tau^{2}\right)+0.20811\left(\tau^{3}\right) \\
-0.04410\left(\tau^{4}\right)\end{array}$ & $220-600 \mathrm{~K}$ & $300 / T$ \\
\hline $\begin{array}{l}\text { Bron, } \\
\text { Chang, } \\
\text { Wolfsberg }\end{array}$ & 7 & $\begin{array}{l}\ln \left(K_{\mathrm{DT}} / 4\right)=-0.00251+0.03334(\tau) \\
-0.16465\left(\tau^{2}\right)+0.11429\left(\tau^{3}\right) \\
-0.02871\left(\tau^{4}\right)\end{array}$ & $220-600 \mathrm{~K}$ & $300 / \mathrm{T}$ \\
\hline $\begin{array}{l}\text { Bron, } \\
\text { Paul }\end{array}$ & 23 & $\begin{array}{l}\ln K_{H D}=0.373949050 \ln T \\
-0.036321650 \tau^{-1}+1.6352125 \\
-0.366926193 \tau+0.056262493 \tau^{2}\end{array}$ & $200-800 \mathrm{~K}$ & $\mathrm{~T} / 500$ \\
\hline $\begin{array}{l}\text { Bron, } \\
\text { Paul }\end{array}$ & 23 & $\begin{array}{l}\ln K_{H T}=0.41144563 \ln \tau \\
-0.21968795 \tau^{-1}+1.7435060 \\
-0.401679993 \tau^{\prime}+0.057340145 \tau^{2}\end{array}$ & $200-800 \mathrm{~K}$ & $T / 500$ \\
\hline $\begin{array}{l}\text { Bron, } \\
\text { Pau1 }\end{array}$ & 23 & $\begin{array}{l}\ln K_{D T}=-0.006034320 \ln T \\
-0.040822500 \tau^{-1}+1.4047699 \\
+0.004119873 \tau-0.002737999 \tau^{2}\end{array}$ & $200-800 \mathrm{~K}$ & $T / 500$ \\
\hline
\end{tabular}




\section{References}

1. M. Wolfsberg, Acct, Chem. Res. 5, 225 (1972).

2. W. J. Moore, Physical Chemlstry (Prentice Hal1, Inc., Englewood Cliffs, N.J., 1962), 3rd ed., P. 622.

3. Ibid., p. 636 .

4. Ibid., pp. 627-631.

5. H. C. Urey, J. Chem. Soc. (London), $\$ 62$ (1947, part 1).

6. J. Bigeleisen and M. G. Mayer, J. Chem. Phys. 15, 261 (1947).

7. J. Bren, C. F. Chang, and M. Wolfsberg, Z. Naturforsch. 28a, 129 (1973;. [This paper refers to many of the earlier papers in this series.]

8. R. D. Bardo and M. Wolfsberg, J. Chem. Phys. 62, 4555 (1975). [Th1s paper has references to earlier work in this area.]

9. M. Wolf sberg, Advan. Chem. Ser. 89, 185 (1969).

10. L. I. Kleinman and M. Wolfsberg, J. Chem. Phys. 60, 4740 (1974).

11. J. Bigeleisen, private communication, (Oct. 5, 1976).

12. L. Haar, A. S. Friedman, and C. W. Beckett, Ideal Gas Thermodynamis Functions and Isotope Exchange Functions for the Diatomic Hydrides, Deuterides, and Tritides, N.B.S. Monograph 20 (U.S. Government Printing office, Washington, D.C., 1961), p. b.

13. G. Herzberg, Molecular Spectra and Molecular Structure, Vol. I (D. Van Nostrand, Princeton, N.J., 1961), 2nd ed., pp. 530-3.

14. J. Bigeleisen, J. Chem. Phys. 23, 2264 (1955).

15. H. C. Urey, F. G. Brickwedde, and G. M. Murphy, Phys. Rev. 40, 1 (1932).

16. W. W. Lozier, P. T. Smith, and W. Bleakney, Phys. Rev. 45, 655 (1934).

17. W. M. Jones, J. Chem. Phys. 16, 1077 (1948).

18. W. M. Jones, J. Chem. Phys. 17, 1052 (1949).

19. W. M. Jones, J. Chem. Phys. 47, 4675 (1967).

20. D. Rittenberg, W. Bleakney, and H. C. Urey, J. Chem. Phys. 2, 48 (1934).

21. A. J. Gould, w. Bleakney, and i. S. Taylor, J. Chem. Phys. 2, 362 (1934).

22. S. O. Thompson and O. A. Schaeffer, J. Chem. Phys. 23, 759 (1955). 
23. J. Bron and S. O. Paul, Faraday Trans. II I, 1294 (1974).

24. G. M. Kurphy, J. Chem. Phys. 5, 637 (1937).

25. H. C. Mattraw, C. F. Pachuck1, and L. N. Dorfman, J. Chem. Phys. 20, 926 (1952).

26. M. Wolf sberg, A. A. M ssa, and J. W. Pyper, A. Chem. Phys, 53, 3138 (1970).

27. G. Herzberg and L. L. Howe, Can. J. Phys. 37, 1636 (1959). 